\title{
What does resilience mean for urban water services?
}

\author{
Ase Johannessen $^{1,2}$ and Christine Wamsler ${ }^{3}$
}

\begin{abstract}
Disasters and climate change impacts, as well as increased water demand, pose serious risks to the provision of sustainable urban water services, e.g., drinking water, sanitation, and safe drainage, especially in cities. These challenges call for a transition toward improved water management, including considerations of "resilience." However, because the resilience concept has multidisciplinary origins it is open to multiple interpretations, which poses a challenge to understanding and operationalizing the concept. We explore how resilience thinking can be translated into urban water practice to develop the conceptual understanding of transitions toward sustainability. The study is based on a literature review, interviews with water experts, as well as four case studies in South Africa, India, Sweden, and the Philippines. We identify seven key principles or attributes of urban water resilience and the related transition process. We find that resilience building needs to discern between and manage three levels (i.e., socioeconomic, external hazard considerations, and larger social-ecological systems) to be sustainable. In addition, we find that human agency is a strong driver of transition processes, with a certain level of risk awareness and risk perception providing one threshold and a certain capacity for action to implement measures and reorganize in response to risks being another. The difficulty of achieving "knowledge to action" derives from the multiple challenges of crossing these two types of identified thresholds. To address long-term trends or stressors, we find an important role for social learning to ensure that the carrying capacity of urban water services is not exceeded or unwanted consequences are created (e.g., long-term trends like salinization and water depletion). We conclude that the resilience term and related concepts add value to understanding and addressing the dynamic dimension of urban water transitions if the key principles identified in this study are considered.
\end{abstract}

Key Words: climate change adaptation; disaster risk reduction; resilience; sustainable cities; urban transition; urban water; water and sanitation

\section{INTRODUCTION}

Disasters, climate change, and rapid urbanization pose a serious risk to the provision of urban water services including safe drinking water, sanitation, and safe drainage, especially in cities (Howard and Bartram 2010, IPCC 2014). Urban growth increases the risk for disasters because it often limits drainage capacity, while at the same time it increases pressure on urban water systems, especially affecting the poor (UN DESA 2014, Wamsler 2014). Thus, humanity is faced with serious challenges to achieve sustainable urban water management in light of growing risks.

In recent years "urban resilience" has become a popular concept to address increasing risks. It has been applied in various fields linked to sustainable development, climate change adaptation, disaster risk management, and reduction and environmental science (Béné 2013, Wamsler 2014, Olsson et al. 2015). However, the concept has multidisciplinary origins, and has been increasingly criticized for its ambiguity (e.g., Olsson et al. 2015) and challenges to operationalize it (Brand and Jax 2007). So what does the resilience concept comprise, and how could it be applied to urban water services?

Although there are many studies that address urban water services in operational guidelines that have the declared aim of improving disaster risk reduction and resilience (e.g., Twigg 2009, UNISDR 2012, Jha et al. 2013, Turnbull et al. 2013) the resilience concept is generally not operationalized, except for one study focusing on water and sanitation (Howard and Bartram 2010). In this paper we investigate how the resilience concept can be systematized, operationalized, and applied to better guide transitions to more sustainable urban water management in cities.

\section{CONCEPTUAL FRAMEWORK}

Resilience of urban water services: definitions and challenges

In the context of disaster risk reduction and management the term resilience is defined as "the ability of a system, community or society exposed to hazards to resist, absorb, accommodate to and recover from the efforts of a hazard in a timely and efficient manner" (UNISDR 2009). In contrast, in the community of research and practice around sustainability and social-ecology, resilience is framed in a more general sense, and "reflects the degree to which a complex adaptive system is capable of selforganization," that is, "the capacity of linked social-ecological systems to absorb recurrent disturbances ... so as to retain essential structures, processes and feedbacks ... and the degree to which the system can build capacity for learning and adaptation" (Adger et al. 2005:1036). A significant difference between the two definitions is that the former implies a positive value for society while many theorists of the latter definition would argue that resilience is value-free (Redman 2014). The latter also refers more explicitly to a multiscalar system with potential for learning and adaptation/ transformation when ecological, political, social, or economic conditions make the existing system in question untenable (Walker et al. 2004, Adger et al. 2005, Folke 2006). Related key concepts used in the analysis of this paper are transitions and transformation, enabling and disabling factors, and thresholds:

\section{Transitions}

In sustainability and social-ecological resilience theory, the notion of transition (in that context often referred to as transformation) is interesting to urban water services in that it holds a promise for learning, reorganization, and improvement (Adger et al. 2005).

${ }^{1}$ Stockholm Environment Institute, ${ }^{2}$ Division of Risk Management and Societal Safety, Centre for Risk Assessment and Management (LUCRAM)

Lund University, Sweden, ${ }^{3}$ Lund University Centre for Sustainability Studies (LUCSUS), Sweden 
Instead of resilience meaning bouncing back to the same (sometimes poor) state as before, resilience dynamics can thus imply an ability to transition from the current situation where many of the world's urban poor suffer from dysfunctional urban water services, to an achievement of, e.g., increased and more equitable access to water, better treatment of wastewater, and better quality water. In transition theory, social learning is central because it contributes to a robust strategy for accelerating and guiding social innovation processes (Loorbach and Rotmans 2010). Improvements through learning can require more or less mental energy, and the outcomes can be more or less "deep": e.g., learning can take place either through already established actions (single-loop learning) or changes in initial frames of reference (or worldviews) such as system boundaries (double-loop learning), or changes in underlying norms and governance structures (triple-loop learning; Huntjens et al. 2012). In disaster risk reduction the emphasis is often on disaster resilience, and hence, related transitions, in the context of sudden crises such as floods (Folke et al. 2010). Although sustainability and social-ecological resilience theory also recognize that transitions can be triggered by external crises, it much more emphasizes the internal adaptive dynamics, including slower processes (Walker and Salt 2012).

\section{Enabling and disabling factors}

Transitions are enabled (or disabled) by context-dependent feedback processes that evolve (or self-organize) the system identity over time (Walker and Salt 2012). As such, the transition process is not determined and linear, but rather an evolving pathway with emergent properties (Turnheim et al. 2015).

\section{Thresholds}

When critical feedback processes change, through, e.g., crises or other disturbances, and the so-called self-organizing capacity cannot recover the system anymore, the system has reached a limit called a threshold (Walker and Salt 2012). Thresholds are of a different nature, where the system can be subject to small changes (no threshold), step changes, or an irreversible or reversible "collapse" or reorganization (Walker and Salt 2012).

\section{Defining the goals of urban water transitions}

In terms of good water governance, integrated water resources management (IWRM) promotes principles for coordinated, sustainable, and equitable development and management of water, land, and related resources (GWP 2000), and is adopted by the majority of the global water community (e.g., UNWATER and GWP 2007). The approach has been further refined, e.g., integrated urban water management (IUWM), "partial IWRM"(Butterworth et al. 2011) and "water sensitive cities" (Brown et al. 2009). The Intergovernmental Panel on Climate Change (IPCC) and others have highlighted the importance of integrating adaptation to climate change in water management (e.g., Zwolsman et al. 2010, IPCC 2014). However, IWRM as a blueprint is not always fit for purpose (Shah 2016); for example, local water managers find it difficult to implement the "extensive and daunting" long list of to do's in IWRM (Butterworth et al. 2011). In addition, some authors argue that sustainable water management inclusive of IWRM cannot be realized without current water management regimes undergoing a transition toward adaptive water management. This means implementing a systematic approach to learning to account for the uncertainties in the system in question (Pahl-Wostl et al. 2007). Given the above background, an improved understanding of resilience in urban water management can contribute to the further development of IWRM / IWRM lite and adaptive water management through the related concepts of transitions, thresholds, and an understanding of what enables or disables transitions toward sustainability.

\section{Exploring resilience transitions in urban water services}

To assess the resilience of urban water services there is a need to define its system boundaries and the disturbances this system is being exposed to (Walker and Salt 2012). This is challenging because the urban water system involves multiple scales depending on users (e.g., households and communities), institutions (e.g., service providers and regulators), technologies, and ecosystems (Howe et al. 2011). The urban water system can also be described in terms of multiple water networks, or sectors, i.e., natural systems (including groundwater and receiving waters), water supply, storm water and sewer system (combined with storm water or separate from it; Butterworth et al. 2011) that includes surface flood pathways created during extreme events (Ellis and Viavattene 2014). The natural systems often link up to water resources and ecosystems at a river basin level where water flows are affected by land use, building distribution, and infrastructure (Ellis and Viavattene 2014). Each of the different systems in the urban water cycle is often considered without cross-reference to the other systems (Butler and Davies 2000). However, in many cases, for example in urban flooding, the complexity of the urban water system requires that it is approached in an integrated way (Ellis and Viavattene 2014). Although the term "system" may be confusing because it can be subject to much interpretation, the term "service" (used in this study) instead focuses the attention to what matters to the user. For example, a physical system will come to an end, but if replaced in due time, the service is maintained (Moriarty et al. 2013). Thus the term "service" is more widely used by the urban water community of practice (cf. Butterworth et al. 2011, Howe et al. 2011).

\section{METHODOLOGY}

The study followed four methodological steps. First, after a literature review we conceptualized how we would apply the term resilience to urban water services, identifying basic elements for building an urban water resilience framework, which guided our empirical work. Second, we carried out interviews with 10 key informants (see Appendix 1 for affiliations) by first introducing the type of disturbances relating to flood and drought and discussing the boundaries of the system/service (see Appendix 2).

The key informants were representing both the WASH (Water, Sanitation and Hygiene) humanitarian and development community, where some had more utility focus and some more on site focus, e.g., hand pumps or latrines. The choice of including the two communities aimed to capture a broad scope of interpretations of the term resilience both from disaster and development settings.

The interview responses (see Appendix 3 for interview questions) were analyzed using the different types of identified (socioeconomic, external hazard, and social-ecological) resilience levels. The responses were then explored in relation to the key elements of transitions, which meant a "zooming in" from the interview questions to the three key concepts: 
Table 1. A summary of the enabling and disabling factors that influence the different resilience levels identified from the empirical data.

\begin{tabular}{|c|c|c|}
\hline & Enabling factors & Disabling factors \\
\hline Socioeconomic resilience & $\begin{array}{l}\text { Technical capacity and knowhow } \\
\text { Policy-science integration } \\
\text { Microgovernance arrangements } \\
\text { Inclusive participation } \\
\text { Accountability } \\
\text { True costs accounting }\end{array}$ & $\begin{array}{l}\text { Lack of practical technical capacity } \\
\text { Education distant to real issues } \\
\text { Power games and political self interest } \\
\text { Unsustainable public preferences } \\
\text { Focus on physical structures rather than capacity related }\end{array}$ \\
\hline $\begin{array}{l}\text { External hazard } \\
\text { resilience }\end{array}$ & $\begin{array}{l}\text { Awareness of climate and disaster risk } \\
\text { Win-wins between effectiveness of daily operations and } \\
\text { hazard preparedness, vulnerability and hazard reduction }\end{array}$ & $\begin{array}{l}\text { Lack of financial and other resources to handle beyond } \\
\text { normal } \\
\text { Lack of knowledge of what increases hazard resilience } \\
\text { High value of cost effectiveness }\end{array}$ \\
\hline $\begin{array}{l}\text { Social-ecological } \\
\text { resilience }\end{array}$ & $\begin{array}{l}\text { Across scales: Interinstitutional coordination; long-term } \\
\text { regulation and policy } \\
\text { Integrated formal and informal urban planning frameworks } \\
\text { (e.g., linking upstream downstream areas) }\end{array}$ & $\begin{array}{l}\text { Local increases of resilience reduce resilience at regional } \\
\text { level } \\
\text { Lack of knowledge on ecosystem-based measures favoring } \\
\text { local structural solutions } \\
\text { Lock-ins, favoring rapid urbanization and economic growth }\end{array}$ \\
\hline
\end{tabular}

1. enabling and disabling factors for resilience;

2. related thresholds;

3. the identification of possible transitions through step change or collapse.

The intention was to further develop the framework and get a sense of the types of interventions that correspond to the different key elements, rather than to arrive at an exhaustive list of examples, measures, or solutions for resilient urban water services.

In the third methodological step, we conducted a comparative case study including Durban (South Africa), Gorakhpur (India), Kristianstad (Sweden), and Cebu (the Philippines). Three criteria were used to select the locations: a high level of water-related risks in terms of flood or drought, or both; a river basin context; and the potential to access relevant data. The case studies included a total of 50 interviews. A common interview protocol was used and interviews were analyzed to assess the identified key elements for urban water resilience and related transitions. In each case, the interviewees included politicians, technical staff (e.g., city council members, urban water specialists, city and environmental planners), private sector (e.g., water and wastewater operators), and civil society representatives, chosen for their potentially different perspectives. Finally, the fourth methodological step included triangulation of the different data through a one-day workshop with the project team, consisting of 11 people. We discussed the findings from the case studies and how they could exemplify the resilience framework.

\section{RESULTS: UNDERSTANDING URBAN WATER RESILIENCE IN PRACTICE}

\section{Disturbances: three levels of urban water resilience}

The responses from the 10 key interviews clearly indicated that the resilience concept can and should be seen in relation to three different types of disturbances (here referred to as resilience levels).

1. Socioeconomic disturbance, i.e., disturbances not associated with external hazards but within the urban water service infrastructure and the entities that manage and govern them. Such disturbances are linked to socioeconomic, political, or institutional and governance structures. Examples of such disturbance include corruption; power dynamics; capacity gaps; increases in bad debt; production, operation, and maintenance costs. Most responses $(62 \%)$ discussed resilience solely in terms of this category.

2. Hazard disturbance, i.e., external hazard-, disaster-, and crises-related disturbances that come from outside the urban water service infrastructure and the entities that manage and govern them. Almost one-quarter of respondents $(23 \%)$ linked resilience to this type of disturbance.

3. Long-term disturbances such as unsustainable resource extraction by the urban water services on the broader socialecological system and vice versa. Fewer responses (15\%) took this perspective.

Enabling and disabling factors

From the key informants' responses and the case studies, we identified various forms of enabling and disabling factors in relation to the three levels of resilience (see Table 1 for a summary).

\section{Socioeconomic resilience}

Resilience in urban water services in relation to socioeconomic disturbances was said to be enabled (or disabled) by two key factors. The first is stakeholders' capacity to drive developments in a more (or less) sustainable direction. In this context, in terms of capacity development, improved technical knowledge and science-policy integration were seen as crucial. In three case studies, i.e., Durban, Gorakhpur, and Cebu, the lack of practical technical capacity in local government was seen as a key barrier, with university education often seen as distant to the real issues.

The second identified enabling or disabling factor is the level of good governance of the many stakeholders who drive the direction of urban water services self-organization and which sometimes disrupt it. In this context, three types of actors were especially mentioned as being potentially disruptive to transitions: informal urban water service providers, politicians, 
and public users. For example, politicians were said to often hijack urban water activities for their own interests, promising the public what they want in times of elections and then do not deliver (Cebu, Durban). The public exert influence by their preferences, which includes, for example, type of solutions and deprioritizing sanitation, e.g., in Gorakhpur, Cebu, and Durban. Four types of measures emerged that could help counteract the negative influences of the three groups of actors: (i) improving governance arrangements using models for inclusive participation, (ii) improving accountability in urban water services, (iii) establishing regulatory accounting (in Table 1 referred to as "true cost accounting"), and (iv) building stakeholder capacity. For example, interviewees reported that governance arrangements for inclusive participation and involvement of multiple stakeholders has increased knowledge and acceptance of urban water interventions. Such local governance arrangements identified by respondents included microresilience planning (see Gorakhpur, Box 1) and the similar model of Purok to assure participation. Purok, a form of traditional community organization, are normally found in rural settings. In Cebu it is being piloted in four peri-urban areas to bring about ownership and change in, e.g., health, waste collection, disaster risk reduction, and microfinance. However, in terms of a community organizing itself to deal with shocks there is a limit to how much it can do, and it generally needs support from higher level authorities and other external agents to keep the services going. "Accountability triangles" between users, service providers, and service authorities were reported to improve accountability. For example, increased awareness about their water entitlements can enable poor communities to discipline providers and influence policy makers to increase public services. At the same time the policy makers can make providers to serve poor people better (World Bank 2003). Finally, the application of regulatory accounting for urban water infrastructure helps reflect its true costs over the life span of the service, with implications for decision making.

\section{Box 1: Microresilience planning in Gorakhpur, India.}

Gorakhpur has approximately 1 million inhabitants. Gorakhpur Environmental Action Group (GEAC) has piloted microresilience planning in the one of its communities. With the participation of the inhabitants, six thematic committees were formed in key themes including water and sanitation and risk-resilient construction. Practical measures were implemented such as improving the wells and the drainage, and establishing a solid waste management service. These efforts have led to changes in the population's hygiene behaviors along with a decrease in water-related diseases, decreased water-logging, better health care, and improved dialogue with the municipality. However, upscaling of this model from the ward to the entire city seems difficult because of the governance arrangements at higher scales, which do not sufficiently support cross-sectoral collaboration.

\section{Hazard resilience of urban water}

Two enabling factors for hazard resilience were mentioned by the interviewees. The first is stakeholders' increased awareness of the risks of climate change and disasters. Several respondents saw improving hazard resilience as fundamental to ensure the functionality and performance of urban water services. Interviewees agreed that the cost of hazard impacts has been increasing because urban water services cannot adequately cope, leading to secondary hazards, such as landslides and disease outbreaks, and far-reaching impacts on communities. This was especially highlighted in the Asian context: people living in the Asia Pacific region are four times more likely to be affected by hazards than people living in Africa, and 25 times more likely than those in Europe or North America (cf., UNESCAP and UNISDR 2010).

The second enabling factor is the existence of win-wins that increase the effectiveness of daily operations, and at the same time ensure that key functions can be replaced during potential hazard events. These win-wins included decentralization processes of urban water services enabling modularity, e.g., if one unit has closed down the other units can still provide the service.

The two most commonly mentioned disabling factors for hazard resilience were, first, the lack of human and financial resources to handle circumstances beyond the "normal" hazard uncertainty and second, the high value placed on cost effectiveness in urban water delivery. The former includes the lack of knowledge on what types of measures, organizations, and governance structures are needed to increase hazard resilience. As an example of the difficulties of grasping risks in planning, an interviewee mentioned participating in a scenario exercise that described traditional hazard scenarios on the first day but then switched on day two (which happened to coincide with the 9/11 events in 2001) to include a wider spectrum of risks. Regarding the latter, the high value placed on cost effectiveness in urban water delivery especially conflicts with increased redundancy, e.g., through backup systems, and robustness, e.g., of materials used, required to increase resilience.

Social-ecological resilience of urban water services

Several interviewees highlighted that local measures aimed at increasing socioeconomic or hazard resilience can reduce resilience at regional and/or national levels, if the wider socialecological system is not adequately considered. Local improvements in urban water service delivery might, for instance, lead to the pollution and salinization of water resources, e.g., because of open access and resultant excessive water use in Cebu (see Box 2); increase demands for water supply in water-scarce areas; or move water-related risks downstream, e.g., when water supply is augmented but the corresponding water treatment and sanitation services are not put in place.

The three most commonly mentioned enabling factors for improving social-ecological resilience of urban water services are listed below. Also, in the literature all three aspects have been identified to be crucial for climate policy integration and mainstreaming (Wamsler 2015, Wamsler and Pauleit 2016).

Box 2: Slow-onset disaster through excessive water use in Cebu City, The Philippines.

In Cebu City, with around 900,000 inhabitants, excessive groundwater pumping rates are resulting in drastic lowering of the groundwater levels and seawater intrusion. Leaking 
Table 2. A summary of the two types of thresholds for the different levels of resilience identified from the empirical data: (1) the threshold for risk and perception of risk and (2) the threshold for action capacity that enables implementing measures and reorganization.

\begin{tabular}{|c|c|c|}
\hline Type of resilience & Threshold for risk and perception of risk & Threshold for action capacity \\
\hline \multirow[t]{4}{*}{ Socioeconomic resilience } & $\begin{array}{l}\text { A certain level of sufficient water supply that satisfies human } \\
\text { needs. Certain norms influencing perception of "sufficient." }\end{array}$ & No identified threshold \\
\hline & A certain level of perceived (dys)functionality of the system. & Responses to fight an epidemic. Triggering measures to \\
\hline & $\begin{array}{l}\text { In case of an epidemic, this is certain. } \\
\text { A certain level of management of the water system. }\end{array}$ & $\begin{array}{l}\text { address underlying vulnerabilities in the urban water system. } \\
\text { Action to reach a certain standard of quality, quantity of } \\
\text { water, etc. fit for human use, as defined by established } \\
\text { indicators. }\end{array}$ \\
\hline & $\begin{array}{l}\text { A variety of different thresholds that are able to be hijacked } \\
\text { for political purposes. }\end{array}$ & $\begin{array}{l}\text { Action on relevant urban water issues (e.g., tenure, access, } \\
\text { flood risk management) in relation to election cycles and } \\
\text { disruptive to ongoing capacity building. }\end{array}$ \\
\hline External hazard resilience & $\begin{array}{l}\text { The extent and patterns of (perceived) climate change-related } \\
\text { floods and its perceived future impact on society. }\end{array}$ & $\begin{array}{l}\text { A level of financial capital for investments available for } \\
\text { disaster-resilient urban water services. }\end{array}$ \\
\hline \multirow[t]{2}{*}{$\begin{array}{l}\text { Social-ecological } \\
\text { resilience }\end{array}$} & $\begin{array}{l}\text { The extent of drought and its perceived future impact on } \\
\text { society in certain societies. }\end{array}$ & $\begin{array}{l}\text { Political decision-making capacity in relation to building } \\
\text { desalination plants, which is disruptive to ongoing change in } \\
\text { terms of integrated demand and supply management. }\end{array}$ \\
\hline & $\begin{array}{l}\text { The extent of water scarcity and pollution and its (perceived) } \\
\text { impact on society. }\end{array}$ & $\begin{array}{l}\text { No threshold identified as no actions have significantly } \\
\text { addressed the problems. }\end{array}$ \\
\hline
\end{tabular}

household septic tanks and open defecation is also causing severe pollution of the groundwater. Although the Water Resources Center (WRC) has been monitoring water quality in 180 wells in the city nearly every year since 1975 , no solutions are in place yet to tap into new sources, or control and enforce groundwater usage. The lack of policy prioritization, inadequate governance arrangements, and financial and human resource constraints add to the problem. At the same time a growing urban population needs access to clean water. WRC is supporting long term capacity building efforts with local water associations to provide water access. However, such access contributes to the unsustainable water outtake at the urban level without proper management of the resource. One member of the water association stated in 2015: "We have still our application (to extract water) pending since 2009 although since the beginning we have been extracting water."

First, enhanced interinstitutional coordination across scales was mentioned as an enabling factor but as very challenging to achieve. Coordination could, for example, be improved by local water and sanitation providers engaging more actively with the environmental and water service authorities. A related disabling factor includes lack of knowledge on ecosystem-based planning and risk reduction (Sudmeier-Rieux 2013), especially important in the context of Kristianstad (see Box 3) where local structural measures dominate in flood risk management.

Second, the importance of regulatory frameworks and policies across scales and with longer time horizons was frequently mentioned, e.g., water safety plans, because they can allow, for instance, better management of water catchment areas (e.g., Kristianstad, Box 3, Wamsler et al. 2014).

Third, integrated formal and informal urban planning frameworks were identified to be crucial to address "lock-ins" mentioned above and ensure that resilience is considered in onthe-ground developments such as mitigating downstream flooding in local drainage initiatives. Despite knowledge of the negative consequences of urban development, strong drivers such as rapid urbanization and short term economic growth override such resilience planning (Wamsler 2015).

Box 3: Kristianstad: Success at local level but lack of integrated frameworks for the river basin.

Kristianstad in Southern Sweden has approximately 81,000 inhabitants in the wider municipality. In Sweden, Kristianstad represents a successful example in flood risk management. However, on closer scrutiny the flood risk approach is largely dominated by local structural solutions, while solutions linked to environmental management at regional and national levels are scarce. This is mainly due to governance arrangements that place decision making about flood risks with municipalities, and does not sufficiently encourage integration between water quality/ environmental management and flood risk management at higher levels.

\section{Thresholds}

Among the many thresholds we found, we identified two common issues where the first is associated with risk and perception of risk, and the second is associated with action capacity, which sometimes involved implementation of a measure or a reorganization (see Table 2 for a summary).

\section{Thresholds for socioeconomic resilience}

From the key informants' responses and the case studies we identified three possible thresholds for socioeconomic resilience of urban water services. The first includes measures such as technical standards (as an enabling capacity for services' functionality where a critical number of buildings, spare parts, etc. need to comply with the standards) and norms influencing user preferences (e.g., some nomadic population groups demand less water volume). These provide thresholds because they can 
dramatically change services' characteristics, structure, and functions. The second threshold is health-related crises (such as epidemics), where nonfunctional urban water services have reached a "threshold of dysfunctionality" where it can transmit contaminants into the system, which can trigger epidemics. However, they also provide an opportunity to address the underlying vulnerabilities in urban water services (e.g., Durban, see section 4.4. transitions through step change). The third threshold is political interventions, mainly related to election cycles, where radical actions are announced just before elections, such as legalization of slum areas, fair water pricing, or the improvement of water access, and already established capacity dissipates when one administration replaces another.

\section{Thresholds for hazard resilience}

Interviewees identified two possible thresholds for hazard resilience of urban water that are supported by the literature. The first is the extent and patterns of (perceived) climate changerelated floods, representing a certain (threshold of) disturbance to the service (cf. IPCC 2014). The second is the financial capital needed for investments (cf. Smits et al. 2011a). This threshold is associated with the actual shift to more disaster-resilient urban water services where the existence (or lack) of targeted budgets can affect the design and extension of the services.

\section{Thresholds for social-ecological resilience}

Two types of thresholds for social-ecological resilience of urban water were identified by the interviewees and are supported by the literature. The first comprises situations where disturbances are anticipated or announced, and reacted to in a maladaptive fashion. For example, the political decision to build desalination plants in response to the so-called Millennium Drought in Australia (1997-2009; cf. Giurco et al. 2014) led in some places to the dismissal of ongoing social change in terms of integrated resource planning, demand management, and planned water restrictions (Giurco et al. 2014). The perceived severity of the (future) disturbance and its impact on society reached a threshold. The second threshold is linked to cases where specific disturbances were not (or could not be) addressed. One of the interviewees gave an example from Lebanon, where, even before the current crisis in Syria began, water resources in Lebanon were overextracted and salinized. The war itself and an additional 1.2 million refugees then eroded and contaminated water resources in various ways, meaning that building back to normality in terms of serving the population that was there before appears hardly possible (cf. Noolkar and Erande 2014). This type of threshold is arguably also passed in some of the case studies in this paper: in Cebu, water resources are overextracted and salinized, and in Durban, Gorakhpur, and Cebu, drinking water is contaminated by wastewater, environmental degradation, water logging, and flooding.

\section{Transitions through step change or collapse}

The analysis of the 10 key interviews and case studies revealed various forms of transitions in relation to the three levels of resilience.

\section{Socioeconomic resilience}

Interviewees mentioned three potential types of transition in relation to socioeconomic resilience of urban water: continuous upgrade of urban water services, improved cross-sector coordination, and the reorganization or collapse of dysfunctional water and sanitation utilities. Several interviewees also identified existing barriers to potential transitions:

- Resistance to change among urban water professionals because of "traditional" career paths in which environmental concerns are not included, and adversity to changing what seemingly works;

- Lack of human resources, lack of coordination within the sector, e.g., between rainwater collection systems, grey water, wetland treatment, and infiltration technologies; and

- Lack of cross-sectoral coordination, especially between the water and sanitation sector and the drainage, waste management, urban planning, disaster risk reduction, housing, and transport sectors (see Box 4).

Box 4: Durban /eThekwini, South Africa: Internationally renowned, but lacking cross-sectoral integration.

The eThekwini Municipal Area (EMA) has about 3.4 million people, which includes some of the smaller towns around the city center. A substantial proportion of the population lives in lowincome townships, including informal settlements. The eThekwini Water and Sanitation Services (EWS), renowned for providing sufficient water to the population, has been replicated across the country and has been awarded internationally for its technical capacity and inventive approach. In spite of this, there is a substantial sectoral approach between water, sanitation, disaster risk reduction (DRR), health, solid waste, catchment management, and vector control. For example, the disaster risk reduction leadership considers "potable water to be [only] an issue for the urban water sector" (Head of cluster for DRR).

\section{Hazard resilience}

The interviewees mentioned two processes in this context that are relevant for hazard resilience of urban water services. First, recurring floods were said to have increased local acceptance of alternative solutions and more sustainable practices, e.g., raised latrines as the pit latrines got flooded. However, interviewees also stated that disasters often do not lead to transitions to better services, but only to minimal recovery of lifesaving functions, especially in low-income contexts. Second, the collapse of an interinstitutional cooperation on climate change adaptation was mentioned as a way to understand how to better set it up; not as an academic-practitioner relationship, but rather as a peer to peer network that enables symmetric relationships and learning. This enabled knowledge building on possible effects of climate change on water services.

\section{Social-ecological resilience of urban water}

Two types of transitions that can lead to social-ecological resilience in urban water services were identified by the interviewees and are supported by the literature. The first type is a shift into a new regime, which presents worsened environmental conditions. For instance, in Lebanon, because of the situation described above, new treatment plants or other solutions to deal 
with new contaminants in the water are needed (cf. UNHCR 2014). Mexico provides another example of such a transition. A salinity crisis between 1961 and 1973 was triggered by overextraction from the Colorado River in the U.S. As a result, Mexico now receives compensation from the U.S., and the areas affected by the increasing salinity were protected (cf. Gottlieb 2012). The second type of transition into a new regime means improvements in urban water services. For example, the implementation of water recycling in Singapore, which was assisted by people's increasing acceptance of using recycled water for drinking (cf. World Bank 2006). Another example is the response to the Millennium Drought in Australia where it can be questioned whether or not the sudden shift to desalination represents a sustainable pathway (cf. Giurco et al. 2014).

\section{DISCUSSION}

We present and discuss seven key principles or attributes of urban water resilience and related transitions that have derived from the results. They provide much needed insights for further conceptualization and clarity in applying the resilience concept to urban water services.

\section{The urban water service: three levels of resilience}

\section{Principle 1}

Our results show the importance of explicitly discerning between three levels of resilience in urban water services (socioeconomic, hazard, social-ecological) through the use of more specific terminology (Fig. 1). We base this on the following two observations:

Fig. 1. Three levels of perceived resilience in the urban water system identified from the empirical data: (1) Socioeconomic operation in focus. (2) External hazard considerations are taken. (3) A larger social-ecological system, e.g., river basin or urban metropolis area. (Icons made by Freepik and Darius Dan from http://www.flaticon.com/.)

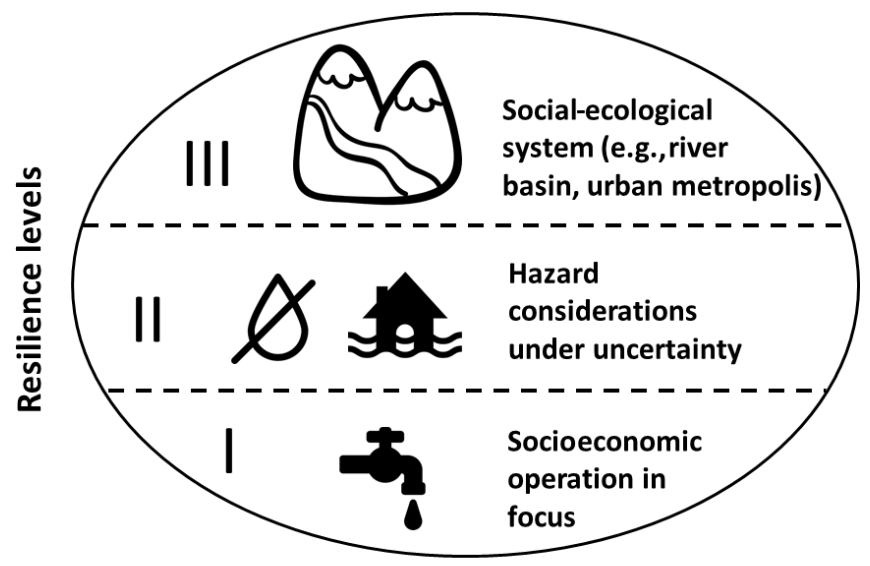

- Most respondents referred implicitly to resilience as relating to disturbances of a socioeconomic nature (the first resilience level), in which the urban water sector invests most (Smits et al. 2011b). This is in contrast to the climate change adaptation and disaster risk-reduction field that focuses on external hazard disturbances (the second resilience level) and has often neglected to consider other types of disturbances, such as social-political processes (Weichselgartner and Kelman 2015). On the other hand the ecosystemoriented community mainly refers to resilience of the socialecological system, which is the third resilience level, comprising a larger scale than the other two (Walker and Salt 2012)

- b. Most respondents referred to all three different levels of resilience, but without being explicit (or conscious) that they were doing so. This shows how different practitioners assume different meanings when using the resilience concept in relation to urban water. This phenomena is contributing to the existing confusion around the resilience terminology (Olsson et al. 2015). Instead, more specific terms and descriptions, such as "resilience to disaster risk" referring to the second resilience level, might be more helpful in contexts where improved urban water services are concerned.

\section{Principle 2}

The existence of three levels of resilience implies that if a truly sustainable water service is to be achieved, all three levels need to be addressed. This means that actors who influence the flow and quality of water have to explicitly consider cross-scale dynamics (cf. Holling and Gunderson 2002). If not, resilience and sustainability can be at odds with each other. This is because resilience is defined and addressed differently, often by different communities of practice, and between the three levels (as described above in Principle 1). For example, in Cebu, a successful example of providing water supply access by an association at the neighborhood level (resilience at level I), is one of many examples of open water access, contributing to overextraction and salinization of groundwater at a larger urban catchment scale (lack of sustainability at level III; see Box 2). Another example is the general consensus that we need a transition toward more sustainable and hazard-resilient cities (UNISDR 2012, Wamsler 2014, ICLEI 2015). However, many urban water services that could be described as resilient (i.e., at level II), such as conventional risk-reduction measures used to flood-proof a society, may involve large structural solutions, which are often unsustainable from an environmental, economic, and/or social point of view (lack of sustainability at level I and/or III; Johannessen and Hahn 2013, Wamsler 2015). On the other hand, developing green infrastructure options such as green roofs or wetlands might provide many ecological and recreational benefits where resilience and sustainability are aligned (e.g., Eastern Research Group, Inc. 2014).

\section{Human agency driving or obstructing the transition process}

\section{Principle 3}

Although urban water is often viewed as a technical issue requiring infrastructure solutions, this study indicates that a key feature of transitions to more sustainable services is an advanced understanding of human and organizational perception and behavior, including individual and institutional needs, desires, wants (motivations), and power issues (cf. Giddens 1982, Partzsch 2015). This means that if such agency-related factors are matched by adequate feedbacks, e.g., adequate policies mirror people's investment logic, it supports human behavior and organization 
in sustainable directions. In this context, our analysis identified feedback mechanisms that need special scrutiny: governance structures and participation, accountability, regulatory accounting, capacity development, and science-policy integration. For example, to strengthen the agency of urban water stakeholders, interviewees stated that it would be important to understand how to better enable community organization, why research institutions engage too little in local change, and why urban water professionals tend to resist change. Better understanding of the underlying human motivations and power struggles of such questions is crucial to support transition, which is also supported by recent sustainability research (Partzsch 2015).

Urban water service performance mainly depends on such agency-related factors that provide the direction of transition processes; that is to say that different agents or stakeholders can either enable or disrupt the pathway toward desired developments. Hence, concepts that aim to operationalize urban water resilience, such as the water sensitive city (Brown et al. 2009), require that transition processes are considered and described in terms of agency, instead of focusing on technologies. The previous attempts to apply the resilience concept to urban water reflect this one-sided focus (Howard and Bartram 2010). The focus on tangible measures and technologies downplays the role of agency in driving transitions, which is also illustrated by the bulk of aid money that flows to projects delivering new taps and toilets rather than (institutional) capacity building (European Court of Auditors 2012, Moriarty 2015).

\section{Principle 4}

Our results show that social learning is a clear driver in transition processes. For example, governance arrangements built on social learning such as the Purok in the Cebu case study, or the micro resilience planning in Gorakhpur, enable different stakeholders and different kinds of knowledge to interact, which alters understanding over time (cf. Feurt 2008). Our results indicate the importance of social learning also when comparing the levels of resilience, considering socioeconomic disturbances, hazards, and social-ecological dynamics across scales. The need for capacity development was highlighted within each level. However, in the context of socioeconomic disturbances, relevant responses focused on improving already established actions (single-loop learning). In the context of external hazard resilience, interviewees highlighted the need to (further) advance initial frames of reference and guiding assumptions, for instance in risk assessment (double-loop learning). The need for such advancement suggests that a lack of capacity in holistic and integrated risk assessments is a barrier for transition to a disaster-resilient city (cf. Rivera et al. 2015). In the context of social-ecological resilience, there were substantially more responses on the need for a social learning effort to develop capacity to influence governance structures at different levels as well as underlying norms (triple-loop learning). A reason for this could be the lack of governance structures or responsible agencies that could drive change and potentially address slow disasters such as salinization and overextraction as found in, for example, Cebu and Gorakhpur. Huntjens et al. (2012) support this finding, stating that complexity and uncertainty on a large scale require institutions to facilitate systemic learning processes to ensure triple-loop learning for more fundamental change. Although some interviewees argued that fundamental change is already happening in the water sector, in terms of a "new order" or paradigm shifts (e.g., upgrading toward more sustainable urban drainage systems, decentralization processes, use of modularity design, and information technology), others regarded these as only incremental adjustments. A trends and scenario analysis at sector level by Smits et al. (2011b) confirms this latter perspective and depicts the urban water sector as being highly conservative, which is perhaps a consequence of the long lifetime of water-related infrastructure. Also, even though modularity is proposed as an important characteristic of water technology in the 21 st century, it is a rather old engineering solution, and there is no clear indication that it supports fundamental change (Spiller et al. 2015).

\section{Principle 5}

Successful urban water transitions involve navigating uncertainty, i.e., finding an appropriate balance between meeting specific or multiple hazards (prioritization) and preparing for eventualities (diversification). Human choices are also, in low-income contexts, very much influenced by ensuring day-to-day livelihoods (Wamsler et al. 2012, World Bank 2013). Especially regarding external hazard disturbances, our results illustrate how recent experience and what we expect to happen in the future makes us downplay very rare or so called "black swan events" (Taleb 2010) illustrated earlier by the scenario development before and after 9/11. In accordance with our findings, some scholars argue that it should never be assumed that risks have been eliminated, which can lead to complacency (e.g., Hollnagel and Fujita 2012). Nevertheless, our findings illustrate that although faced with uncertainty, there is a preference for investing in more tangible measures that tackle more predictable and urgent problems, such as recurring small-scale floods, or providing access. Doing anything differently is challenging given the perceived lack of human and financial resources to handle circumstances beyond the normal hazard uncertainty, and the high value placed on cost effectiveness in urban water service delivery.

\section{Principle 6}

Our study highlights two key thresholds for transition in urban water services (Fig. 2). The first threshold is related to a certain level of perceived risk, i.e., the perception that a certain disturbance will have a certain impact (or consequence) on a given system (see a. in Figure 2). The required levels and process to reach them is context dependent and involves many different actors; individual professionals may be the first ones to identify the risk, but various processes of social learning are needed to build this awareness with decision makers and the public (Johannessen and Hahn 2013). The level of risk awareness is influenced by socio-cultural standards, e.g., preferences and norms, in contrast to physical standards. For example, water use and demand is different between, e.g., rural nomads and urbanites who will perceive risks at different water volumes. In the case of Australia's Millennium Drought, a perceived threshold of future climate risk was identified that in the end never materialized in physical reality. Awareness of a risk can be slow to develop, especially of slowly developing stressors, as shown by, e.g., acid rain, biodiversity loss, climate change, droughts, deforestation, desertification, and famines (Mosley 2015). Monitoring such changes requires reliable monitoring systems and knowledge building over time which is also stored in social memory (Folke 2006). 
Fig. 2. Two types of thresholds were identified from the empirical data relevant for the transition process in urban water services: (1) risk awareness and perception and (2) action capacity.

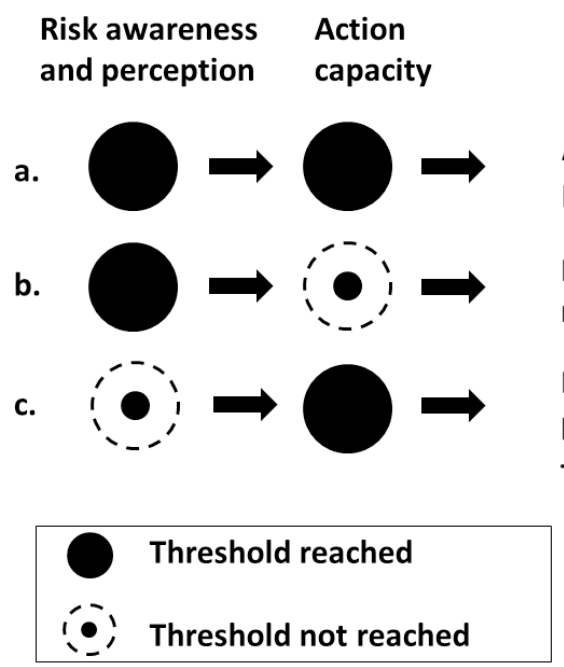

The second type of identified key threshold is related to a certain level of action capacity to act on the perceived risk, e.g., financial capital and capacity to take a political decision. For example, during Australia's Millennium Drought a shift to desalination provided a solution to growing demands in a water-depleted environment (Turner et al. 2010). This represents an action capacity in terms of decision making, although there is disagreement whether this led to sustainable management (see a. in Fig. 2). In cases where the situation might be even more pressing, and the risk awareness is available, such as in Cebu, Gorakhpur, and Durban, there seems to be a lack of action capacity to generate political decisions and implement action (see b. in Fig. 2). This gap between knowledge of a risk and acting on it has also been identified in the literature (Kolmuss and Agyeman 2002, Shove 2010). Earlier studies have likened such thresholds to a context specific "critical mass" to push a process that makes a social movement or political decision inevitable (Werners et al. 2013). This may be a question of translating science to policy, and the need for certainty in investments, illustrated by the social inertia to act on climate change (Bradshaw and Borchers 2000). The important role of (risk) perception for the crossing of thresholds may be key to understanding why societies endure certain risks. It is known that shared (and outdated) worldviews that do not match reality can be subject to manipulation and control by powerful interests (cf. Foucault 1984). As such they can resist building risk awareness or capacity for action if it does not benefit their interests.

\section{Principle 7}

Although transition through collapse was not well received by our interviewees, because it is generally not seen as very compatible with a conservative risk-averse water industry, our findings suggest an important role for the related concept of reorganization. Transition through reorganization was often associated with some initial resistance to accepting new information and abandoning accepted truths for change to happen, which is associated with deeper learning (Schein 1999). Such change was linked to the breakdown of (corrupt) entities, which become disabled through the establishment of better accountability mechanisms, open routes for improvement and presumably more transparency. One estimate is that 20 to $70 \%$ of resources could be saved if transparency would be optimized and corruption eliminated (Transparency International 2008). Transition through collapse was more easily associated with the outbreak of disasters and epidemics such as cholera outbreaks, which was able to spark policy change and investments at the national level in Durban (Gounden et al. 2006) and in terms of acceptability of different sanitation options.

It is important to highlight here that the transition toward improved economic status may not always lead to higher disaster resilience. For example, as countries and cities get richer and more interconnected, and as economic activity becomes more urbanized with sensitive infrastructure, disasters can cause much greater economic damage than previously, which impacts urban water services (Wamsler and Brink 2016). In this context, urban water resilience better describes the dynamic functioning of a system rather than a desired outcome in the progression toward improved water management.

The different principles and their interlinkages are illustrated in Figures 1-3. Figure 3 provides the conceptual model for the transition process into a more sustainable and hazard resilient state of urban water.

Fig. 3. A conceptual model for the process of transition into a more sustainable and hazard-resilient state of urban water. Here, all three levels of resilience need to be taken into account (socioeconomic, external hazards, and social-ecological scale) so that focus on resilience at one level does not compromise the sustainability of another (1-2), where enabling and disabling factors for human agency (3) influence the process of social learning, monitoring, and memory (4). Actors need to navigate uncertainty through prioritization and diversification (5). When thresholds of risk awareness and action capacity are reached (6), measures are put in place, and/or a reorganization occurs (7) and the system makes a transition. (Icons made by Freepik from $\underline{h t t p: / / w w w . f l a t i c o n . c o m / .) ~}$

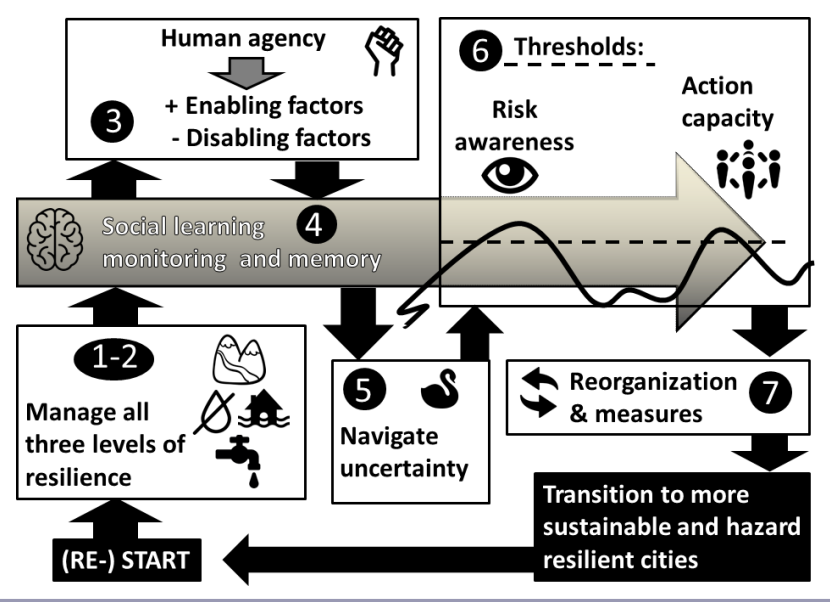




\section{CONCLUSIONS}

Through literature review, interviews, and four case studies we explore how resilience thinking can be translated into urban water practice. We further develop the conceptual understanding of transitions toward improved management and sustainability in urban water services (illustrated in Fig. 3).

We conclude that resilience-related concepts can add much value to understanding and addressing the dynamic dimension of urban water transitions if the seven key principles identified in this study are considered. This does not necessarily support the use of the term resilience per se, but of its principal components, which can be linked to other conceptual models and frameworks. Although we have tried to capture a broad scope of interpretations of the term resilience both from disaster and development settings, the results do not provide an exhaustive list of interventions, but only illustrating the key principles adding to existing theory linked to IWRM.

Based on our assessment, the seven key principles or attributes are as follows:

Principle 1: Three levels of resilience: Resilience in urban water services needs to discern between socioeconomic disturbances, hazard considerations, and social-ecological dynamics across scales. Explicit reference to the identified three levels of resilience would enable a less conflictive and more operational use of related concepts. The understanding that resilience not only concerns external disturbances is in line with how the term is applied to analyses of ecosystems, also considering (internal) socialecological dynamics of slow-onset disasters and crises across scales. However, it is not in line with current discourse in risk reduction and climate change adaptation, where resilience is still too often used only in relation to external hazards (Eriksen et al. 2015, Weichselgartner and Kelman 2015). Nevertheless, debates on transformational adaptation and differential vulnerability are increasingly providing more nuanced perspectives to address the roots of climate and disaster risk through action that changes the fundamental attributes of a system (Agard et al. 2014, Wamsler 2014, Eriksen et al. 2015).

Principle 2: Integrated resilience-sustainability planning: If a sustainable water service is to be achieved, all three levels of resilience need to be addressed. Cross-scale dynamics in urban water mean that resilience and sustainability can be at odds with each other. Efforts to enhance resilience to socioeconomic and external hazard disturbances, e.g., improve local access to water for citizens, in fact may erode more large-scale social-ecological resilience, e.g., create regional water scarcity. Thus, consideration must be given to sustainability of the whole system.

Principle 3: Human agency focus: Our results show a strong role for a range of diverse urban water actors to drive transitions, and there is a need to better understand, e.g., through more research, how their perception, behavior, and related power struggles can better align with desired transitions. In contrast, uncertainty in climate and disaster projections is a barrier to action, which leads to a preference for investing in more tangible measures such as infrastructure. The focus on infrastructure is reflected in previous attempts in applying the resilience concept to urban water (Brown et al. 2009, Howard and Bartram 2010).

Principle 4: Social learning: Social learning is a key driver of transitions by supporting capacity building to reach thresholds (see below) and reorganization to a new development pathway. The direction of such a pathway in terms of sustainability is in turn enabled and disabled by certain factors. Especially in the context of social-ecological resilience (resilience level III) deep social learning, achieved through, e.g., cross-scale governance arrangements, has an important role to play to support fundamental change to potentially address slow disasters such as salinization and water overextraction, which can influence the other levels of resilience.

Principle 5: Navigating uncertainty (prioritize and diversify): Resilience transitions in urban water require an appropriate balance between meeting specific hazards (prioritization) and other pressing needs, e.g., day-to-day livelihood, while dealing with high levels of hazard uncertainties (diversification).

Principle 6: Risk perception and action capacity as thresholds: A critical mass or threshold for urban water is needed, both in terms of risk awareness and perception, and also in terms of action capacity to push a process that makes a social movement or political decision inevitable. In this context, the results indicate that although it is important to have in place mechanisms to build risk awareness (monitoring systems, knowledge building arrangements, and institutional memory) to reach a certain threshold, it is crucial to also build action capacity in terms of collaboration and learning at multiple levels to reach the second threshold.

The difficulty of achieving "knowledge to action" derives from the multiple challenges of crossing the identified thresholds associated with these capacities, including changing shared worldviews and perception, qualities that are easily manipulated by powerful interests. However, although these thresholds can be crossed, the achieved action is not necessarily sustainable. In this context, we argue for enabling capacity building focusing on these two thresholds, especially concerning slowly developing stressors where sustainability is most at risk and also most challenging to address.

Principle 7: Supporting reorganization: The resilience concept implies that the reorganizing of failing structures (such as organizations) is necessary for a transition into something better. Facilitating change processes aimed at supporting reorganization of (dysfunctional) urban water systems might be important ways to push transitions forward, and should be further explored in research and practice. Arguably, the more fundamental change is required, the more resistance against new ways of thinking needs to be overcome.

Responses to this article can be read online at: http://www.ecologyandsociety.org/issues/responses. $\mathrm{php} / 8870$

\section{Acknowledgments:}

This paper is an outcome of the WASH \& RESCUE project ( Grant number MSB: 211-946) financed by The Swedish Civil Contingencies Agency (MSB). It has also received financial support from the Transforming Development and Disaster Risk Initiative at SEI, financed by the Swedish International Development Cooperation (Sida). The research has also benefited 
from one of the authors' "Sustainable Urban Transformation for Climate Change Adaptation" project financed by the Swedish Research Council FORMAS. We are grateful to Erik Rottier, Karlee Johnson, Guoyi Han, Frank Thomalla, Asa Gerger Swartling, John Forrester, Sarah Dickin, and Linn Persson, as well as Tom Gill and Rajesh Daniel for editing the paper. We are grateful for the many constructive comments by two anonymous reviewers, the editor of E\&S, and Stef Smits. Many thanks also to the many water and sanitation professionals who generously volunteered their time and knowledge to support this work.

\section{LITERATURE CITED}

Adger, W. N., T. P. Hughes, C. Folke, S. R. Carpenter, and J. Rockström. 2005. Social-ecological resilience to coastal disasters. Science 309:1036-1039. http://dx.doi.org/10.1126/science.1112122

Agard, J., E. L. F. Schipper, J. Birkmann, M. Campos, C. Dubeux, Y. Nojiri, L. Olsson, B. Osman-Elasha, M. Pelling, M. J. Prather, M. G. Rivera-Ferre, O. C. Ruppel, A. Sallenger, K. R. Smith, and A. L. St. Clair. 2014. Annex II Glossary. Pages 1757-1758 in C. B. Field, V. R. Barros, D. J. Dokken, K. J. Mach, M. D. Mastrandrea, T. E. Bilir, M. Chatterjee, K. L. Ebi, Y. O. Estrada, R. C. Genova, B. Girma, E. S. Kissel, A. N. Levy, S. MacCracken, P. R. Mastrandrea, and L. L. White, editors. Climate change 2014: impacts, adaptation, and vulnerability. Contribution of Working Group III to the Fifth Assessment Report of the Intergovernmental Panel on Climate Change. Cambridge University Press, Cambridge, UK.

Béné, C. 2013. Towards a quantifiable measure of resilience. IDS Working Papers 434:1-27. http://dx.doi.org/10.1111/ j.2040-0209.2013.00434.x

Bradshaw, G. A., and J. G. Borchers. 2000. Uncertainty as information: narrowing the science-policy gap. Ecology and Society 4(1):7. http://dx.doi.org/10.5751/es-00174-040107

Brand, F. S., and K. Jax. 2007. Focusing the meaning(s) of resilience: resilience as a descriptive concept and a boundary object. Ecology and Society 12(1):23. http://dx.doi.org/10.5751/ es-02029-120123

Brown, R. R., N. Keath, and T. H. F. Wong. 2009. Urban water management in cities: historical, current and future regimes. Water Science and Technology 59(5):847-855. http://dx.doi. org/10.2166/wst.2009.029

Butler, D., and J. W. Davies. 2000. Urban drainage. Spon Press, London, UK.

Butterworth, J., P. McIntyre, and C. da Silva Wells, editors. 2011. SWITCH in the city: putting urban water management to the test. IRC International Water and Sanitation Centre, The Hague, The Netherlands. [online] URL: $\underline{\text { http://www.ircwash.org/sites/default/ }}$ files/Butterworth-2011-SWITCH_1.pdf

Eastern Research Group, Inc. 2014. Economic assessment of green infrastructure strategies for climate change adaptation: pilot studies in the Great Lakes Region. National Oceanic and Atmospheric Administration Coastal Services Center, Charleston, South Carolina, USA. [online] URL: https://coast.noaa.gov/data/ digitalcoast/pdf/climate-change-adaptation-pilot.pdf
Ellis, J. B., and C. Viavattene. 2014. Sustainable urban drainage system modeling for managing urban surface water flood risk. CLEAN Soil, Air, Water 42(2):153-159. http://dx.doi. org/10.1002/clen.201300225

Eriksen, S. H., A. J. Nightingale, and H. Eakin. 2015. Reframing adaptation: the political nature of climate change adaptation. Global Environmental Change 35:523-533. http://dx.doi. org/10.1016/j.gloenvcha.2015.09.014

European Court of Auditors. 2012. European Union development assistance for drinking water supply and basic sanitation in SubSaharan countries. Special Report No 13. European Union, Luxembourg. http://dx.doi.org/10.2865/10664

Feurt, C. B. 2008. Collaborative learning guide for ecosystem management. Environmental Studies Faculty Publications. Paper 5. University of New England, Biddeford, Maine, USA. [online] URL: http://dune.une.edu/env facpubs/5

Folke, C. 2006. Resilience: the emergence of a perspective for social-ecological systems analyses. Global Environmental Change 16(3):253-267. http://dx.doi.org/10.1016/j.gloenvcha.2006.04.002

Folke, C., S. R. Carpenter, B. Walker, M. Scheffer, T. Chapin, and J. Rockström. 2010. Resilience thinking: integrating resilience, adaptability and transformability. Ecology and Society 15(4):20. [online] URL: http://www.ecologyandsociety.org/vol15/iss4/ art20/

Foucault, M. 1984. The Foucault reader. P. Rabinow, editor. Pantheon Books, New York, New York, USA.

Giddens, A. 1982. Hermeneutics and social theory. Pages 1-17 in A. Giddens. Profiles and critiques in social theory. University of California Press, Berkeley California, USA. http://dx.doi. org/10.1007/978-1-349-86056-2 1

Giurco, D. P., A. Turner, S. Fane, and S. B. White. 2014. Desalination for urban water: changing perceptions and future scenarios in Australia. Chemical Engineering Transactions 42:13-18. http://dx.doi.org/10.3303/CET1442003

Global Water Partnership (GWP). 2000. Integrated water resources management. Technical Advisory Committee (TAC) Background Paper No. 4. GWP, Stockholm, Sweden.

Gottlieb, J. 2012. Salinity crisis in the borderlands: the Mexicali Campesino's fight for Colorado River water in the Delta, 1961-1973. Thesis, Columbia University, New York, New York, USA. [online] URL: http://hdl.handle.net/10022/AC:P:13192

Gounden, T., B. Pfaff, N. Macleod, and C. Buckley. 2006. Sustainable development of water resources, water supply and environmental sanitation. Provision of free sustainable basic sanitation: the Durban experience. 32nd WEDC International Conference, Colombo, Sri Lanka. Water, Engineering and Development Centre, Loughborough University, UK. [online] URL: http://wedc.lboro.ac.uk/resources/conference/32/Gounden. pdf

Holling, C. S., and L. H. Gunderson. 2002. Resilience and adaptive cycles. Pages 25-62 in L. H. Gunderson and C. S. Holling, editors. Panarchy: understanding transformations in human and natural systems. Island, Washington D.C., USA. 
Hollnagel, E., and Y. Fujita. 2012. The Fukushima disaster systemic failures as the lack of resilience. Nuclear Engineering and Technology 45(1):13-20. http://dx.doi.org/10.5516/net.03.2011.078

Howard, G., and J. Bartram. 2010. Vision 2030: the resilience of water supply and sanitation in the face of climate change. World Health Organization, Geneva, Switzerland.

Howe, C., J. Butterworth, I. Smout, A. M. Duffy, and K. Vairavamoorthy. 2011. Sustainable water management in the city of the future. Findings from the SWITCH Project 2006-2011. UNESCO-IHE, Delft, The Netherlands. [online] URL: http:// www.switchurbanwater.eu/outputs/pdfs/Switch_- Final_Report. pdf

Huntjens, P., L. Lebel, C. Pahl-Wostl, J. Camkin, R. Schulze, and N. Kranz. 2012. Institutional design propositions for the governance of adaptation to climate change in the water sector. Global Environmental Change 22(1):67-81. http://dx.doi. org/10.1016/j.gloenvcha.2011.09.015

ICLEI (Local Governments for Sustainability). 2015. Sustainable city. ICLEI, Bonn, Germany. [online] URL: http://www.iclei.org/ activities/agendas/sustainable-city.html

Intergovernmental Panel on Climate Change (IPCC). 2014. Climate Change 2014: synthesis report. Contribution of Working Groups I, II and III to the Fifth Assessment Report of the Intergovernmental Panel on Climate Change. IPCC, Geneva, Switzerland.

Jha, A. K., T. W. Miner, and Z. Stanton-Geddes, editors. 2013. Building urban resilience: principles, tools, and practice. The World Bank, Washington, D.C., USA. http://dx.doi.org/10.1596/978-0$\underline{-8213-8865-5}$

Johannessen, Å., and T. Hahn. 2013. Social learning towards a more adaptive paradigm? Reducing flood risk in Kristianstad Municipality, Sweden. Global Environmental Change 23 (1):372-381. http://dx.doi.org/10.1016/j.gloenvcha.2012.07.009

Kolmuss, A., and J. Agyeman. 2002. Mind the gap: Why do people act environmentally and what are the barriers to proenvironmental behavior? Environmental Education Research 8 (3):239-260. http://dx.doi.org/10.1080/13504620220145401

Loorbach, D., and J. Rotmans. 2010. The practice of transition management: examples and lessons from four distinct cases. Futures 42(3):237-246. http://dx.doi.org/10.1016/j.futures.2009.11.009

Moriarty, P. 2015. Paying the piper: 3 things donors can do to drive real change. Huffington Post, 15 November. [online] URL: http://www.huffingtonpost.com/patrick-moriarty/paying-the-piper-3things-donors-can-do-to-drive-real-change b 8303668.html

Moriarty, P., S. Smits, J. Butterworth, and R. Franceys. 2013. Trends in rural water supply: towards a service delivery approach. Water Alternatives 6(3):329-349.

Mosley, S. 2015. A disaster in slow motion, the smoke menace in urban-industrial Britain. Pages 94-111 in H. Egner, M. Schorch, and M. Voss, editors. Learning and calamities. Practices, interpretations, patterns. Routledge studies in environment, culture and society. Taylor \& Francis, New York, New York, UK.

Noolkar, G., and D. Erande. 2014. The hydro-insecure crisis of survival in the Middle East. Strategic Foresight Group, Mumbai,
India. [online] URL: http://strategicforesight.com/ publication_pdf/19317hydro-insecure.pdf

Olsson, L., A. Jerneck, H. Thoren, J. Persson, and D. O'Byrne. 2015. Why resilience is unappealing to social science: theoretical and empirical investigations of the scientific use of resilience. Science Advances 1(4):e1400217. http://dx.doi.org/10.1126/ sciadv. 1400217

Organisation for Economic Co-operation and Development (OECD). 2014. Guidelines for resilience systems analysis. OECD, Paris, France. [online] URL: http://www.oecd.org/dac/Resilience Systems Analysis FINAL.pdf

Pahl-Wostl, C., J. Sendzimir, P. Jeffrey, J. Aerts, G. Berkamp, and K. Cross. 2007. Managing change toward adaptive water management through social learning. Ecology and Society 12 (2):30. http://dx.doi.org/10.5751/es-02147-120230

Partzsch, L. 2015. No change without power - an agenda for a multidimensional understanding of power in sustainability research. [Translated from the German] GAIA - Ecological Perspectives for Science and Society 24(1):48-56. http://dx.doi. org/10.14512/gaia.24.1.10

Redman, C. L. 2014. Should sustainability and resilience be combined or remain distinct pursuits? Ecology and Society 19 (2):37. http://dx.doi.org/10.5751/ES-06390-190237

Rivera, C., H. Tehler, and C. Wamsler. 2015. Fragmentation in disaster risk management systems: a barrier for integrated planning. International Journal of Disaster Risk Reduction 14:445-456. http://dx.doi.org/10.1016/j.ijdrr.2015.09.009

Schein, E. H. 1999. The corporate culture survival guide: sense and nonsense about cultural change. Jossey-Bass, San Francisco, California, USA.

Shah, T. 2016. Increasing water security: the key to implementing sustainable development goals. Background papers no 22. Global Water Partnership Technical Committee, Stockholm, Sweden.

Shove, E. 2010. Beyond the ABC: climate change policy and theories of social change. Environment and Planning $A 42$ (6):1273-1285. http://dx.doi.org/10.1068/a42282

Smits, S., C. Dietvorst, J. Verhoeven, and J. Butterworth. $2011 b$. Scanning the 2020 horizon: an analysis of trends and scenarios in the water, sanitation and hygiene sector. Occasional Paper Series 45. IRC International Water and Sanitation Centre, The Hague, The Netherlands. [online] URL: http://www.ircwash.org/sites/ default/files/Smits-2011-Scanning.pdf

Smits, S., J. Verhoeven, P. Moriarty, C. Fonseca, and H. Lockwood. 2011a. Arrangements and cost of providing support to rural water service providers. WASHCost working paper 5. IRC International Water and Sanitation Centre, The Hague, The Netherlands. [online] URL: http://www.ircwash.org/sites/default/ files/Smits-2011-Arrangements.pdf

Spiller, M., J. H. G. Vreeburg, I. Leusbrock, and G. Zeeman. 2015. Flexible design in water and wastewater engineering - definitions, literature and decision guide. Journal of Environmental Management 149:271-81. 10.1016/j.jenvman.2014.09.031 http:// dx.doi.org/10.1016/j.jenvman.2014.09.031 
Sudmeier-Rieux, K. 2013. Ecosystem approach to disaster risk reduction: basic concepts and recommendations to governments, with a special focus to Europe. A special publication for the Council of Europe, European and Mediterranean Major Hazards Agreement (EUR-OPA), Strasbourg, France.

Taleb, N. N. 2010. The black swan - the impact of the highly improbable. Random House, New York, New York, USA.

Transparency International. 2008. Global corruption report 2008: corruption in the water sector. Cambridge University Press, Cambridge, UK. [online] URL: http://www.transparency.org/ whatwedo/pub/global_corruption_report_2008_corruption_in_the water sector

Turnbull, M., C. L. Sterrett, and A. Hilleboe. 2013. Toward resilience: a guide to disaster risk reduction and climate change adaptation. Practical Action, Warwickshire, UK. http://dx.doi. org/10.3362/9781780440026

Turner, A., J. Willets, S. Fane, D. Giurco, A. Kazaglis, and S. White. 2010. Guide to demand management. Services Association of Australia, Sydney, Australia.

Turnheim, B., F. Berkhout, F. Geels, A. Hof, A. McMeekin, B. Nykvist, and D. van Vuuren. 2015. Evaluating sustainability transitions pathways: bridging analytical approaches to address governance challenges. Global Environmental Change 35:239-253. http://dx.doi.org/10.1016/j.gloenvcha.2015.08.010

Twigg, J. 2009. Characteristics of a disaster-resilient community: a guidance note. University College of London, London, UK. [online] URL: http://discovery.ucl.ac.uk/1346086/1/1346086.pdf

United Nations Department of Economic and Social Affairs (UN DESA). 2014. World urbanization prospects: the 2014 revision, highlights. United Nations, New York, New York, USA.

United Nations Economic and Social Commission for Asia and the Pacific (UNESCAP), and United Nations International Strategy for Disaster Risk Reduction (UNISDR). 2010. The Asia Pacific disaster report, 2010: protecting development gains reducing disaster vulnerability and building resilience in Asia Pacific. Economic and Social Commission for Asia and the Pacific (ESCAP), Bangkok, Thailand and The United Nations Office for Disaster Reduction (ISDR), Geneva, Switzerland.

United Nations High Commissioner for Refugees (UNHCR). 2014. Lebanon: Monthly update: Dec 2014. UNHCR, Geneva, Switzerland. [online] URL: https://data.unhcr.org/syrianrefugees/ download.php?id=8154

United Nations International Strategy for Disaster Risk Reduction (UNISDR). 2009. Terminology on disaster risk reduction. UNISDR, Geneva, Switzerland. [online] URL: http:// www.unisdr.org/we/inform/terminology

United Nations International Strategy for Disaster Risk Reduction (UNISDR). 2012. How to make cities more resilient: a handbook for local government leaders. UNISDR, Geneva, Switzerland. [online] URL: http://www.unisdr.org/we/inform/ publications/26462

United Nations Water and Global Water Partnership (UNWATER and GWP). 2007. Roadmapping for advancing integrated water resources management (IWRM) processes. UN
WATER, New York, New York, USA and GWP, Stockholm, Sweden. [online] URL: http://www.unwater.org/downloads/ UNW ROADMAPPING IWRM.pdf

Walker, B., C. S. Holling, S. R. Carpenter, and A. Kinzig. 2004. Resilience, adaptability and transformability in social-ecological systems. Ecology and Society 9(2):5. http://dx.doi.org/10.5751/ es-00650-090205

Walker, B., and D. Salt. 2012. Resilience practice: building capacity to absorb disturbance and maintain function. Island, Washington, D.C., USA. http://dx.doi.org/10.5822/978-1-61091-231-0

Wamsler, C. 2014. Cities, disaster risk, and adaptation. Routledge Series on Critical Introduction to Urbanism and the City. Routledge, London, UK.

Wamsler, C. 2015. Mainstreaming ecosystem-based adaptation: transformation toward sustainability in urban governance and planning. Ecology and Society 20(2):30. http://dx.doi. org/10.5751/es-07489-200230

Wamsler, C., and E. Brink. 2016. The urban domino effect: a conceptualization of cities' interconnectedness of risk. International Journal of Disaster Resilience in the Built Environment 7(2):80-113. http://dx.doi.org/10.1108/ijdrbe-01-2015-0001

Wamsler, C., E. Brink, and O. Rantala. 2012. Climate change, adaptation, and formal education: the role of schooling for increasing societies' adaptive capacities in El Salvador and Brazil. Ecology and Society 17(2):2. http://dx.doi.org/10.5751/es-04645-170202

Wamsler, C., C. Lüderitz, and E. Brink. 2014. Local levers for change: mainstreaming ecosystem-based adaptation into municipal planning to foster sustainability transitions. Global Environmental Change 29:189-201. http://dx.doi.org/10.1016/j. gloenvcha.2014.09.008

Wamsler, C., and S. Pauleit. 2016. Making headway in climate policy mainstreaming and eosystem-based adaptation: two pioneering countries, different pathways, one goal. Climatic Change 137(1):71-87. http://dx.doi.org/10.1007/s10584-016-1660ע

Weichselgartner, J., and I. Kelman. 2015. Geographies of resilience: challenges and opportunities of a descriptive concept. Progress in Human Geography 39(3):249-267. http://dx.doi. org/10.1177/0309132513518834

Werners, S. E., S. Pfenninger, E. van Slobbe, M. Haasnoot, J. H. Kwakkel, and R. J. Swart. 2013. Thresholds, tipping and turning points for sustainability under climate change. Current Opinion in Environmental Sustainability 5(3-4):334-340. http://dx.doi. org/10.1016/j.cosust.2013.06.005

World Bank. 2003. World development report 2004: making services work for poor people. The World Bank, Washington, D. C., USA and Oxford University Press, Oxford, UK. [online] URL: http://siteresources.worldbank.org/INTMENA/Resources/ChiefEconomist/PDF/report.pdf

World Bank. 2006. Dealing with water scarcity in Singapore: institutions, strategies, and enforcement. Background Paper No. 4. World Bank Analytical and Advisory Assistance (AAA) Program China: Addressing Water Scarcity. Environment and Social Development East Asia and Pacific Region. The World Bank, 
Washington, D.C., USA. [online] URL: http://siteresources. worldbank.org/INTEAPREGTOPENVIRONMENT/Resources/ WRM Singapore experience EN.pdf

World Bank. 2013. World development report 2014: risk and opportunity. Managing risk for development. The World Bank, Washington, D.C., USA. [online] URL: http://elibrary. worldbank.org/doi/book/10.1596/978-0-8213-9903-3

Zwolsman, G., D. Vanham, P. Fleming, C. Davies, A. Lovell, D. Nolasco, O. Thorne, R. de Sutter, B. Fülöp, P. Satuffer, Å. Johannessen. 2010. Climate change and the water industry: practical responses and actions. Perspectives on water climate adaptation. World Water Council (WWC), Cooperative Programme on Water and Climate (CPWC), The World Conservation Union (IUCN) and International Water Association (IWA), Amsterdam, The Netherlands. 


\section{Appendix 1:}

Affiliations of the ten key informants:

1. Senior Programme Officer, IRC, The Netherlands (Development WASH);

2. Consultant, ResilientWASH, Sweden (Humanitarian WASH);

3. Senior Advisor for resilience and sanitation in Emergencies (SanE), Swedish Red Cross (Humanitarian WASH);

4. Senior WASH Adviser, Norwegian Refugee Council (Humanitarian WASH);

5. Director, ForEvaSolutions, USA (Utility operations);

6. Climate Resiliency Group, Seattle Public Utilities, USA (Utility operations);

7. Asia Urban Programme Manager, Oxfam GB Regional Centre, Bangkok, Thailand (Development WASH);

8. WASH Specialist, UNICEF;

9. Programme Coordinator, International Water Association (IWA), Geneva;

10. Advisor, Cities Development Initiative for Asia (CDIA). 


\section{Appendix 2:}

Introduction given to the interviewees - System boundaries and disturbances

We first presented to the interviewees how we defined the scope for the interview questions on resilience. For the system being affected by a disturbance we first assumed urban water "system", allowing an open ended discussion about what this consisted of. However after some discussions with one of the interviewees we assumed urban water "services". Different disturbances were throughout the interviews presented as a range using the definition by OECD (2014):

1. Covariate shocks - infrequent events with an impact on almost everyone in the target group, such as violent conflict, extreme flood or currency devaluations.

2. Idiosyncratic shocks - significant events that specifically affect individuals and families, such as the death of the main breadwinner or the loss of income-generating activity

3. Frequent small impact events - seasonal shocks, such as annual flooding linked to the rainy season, food market price changes, or recurring shocks such as frequent displacement or endemic cholera in particular communities

4. Long term stresses - long term trends, weakening the potential of a system and deepening the vulnerability of its actors, like increased pollution, deforestation, exchange rate fluctuations and electoral cycles. 


\section{Appendix 3:}

Interview questions

Each interview question was introduced by referring to Walker \& Salt (2012).

\section{How would you translate "Self organization" to WASH systems?}

If a part of a system is changed most of the time the system can handle it by "selforganizing" i.e. absorbing the disturbance, reorganize, and perform in the way it didretaining its identity. But sometimes the system can't cope with the change and begins behaving in some other (often undesirable) way.

\section{In this discussion, can you identify any "Thresholds" and their interactions?}

Thresholds are the limits to how much a self-organizing system can be changed and still recover. Beyond those limits it functions differently because some critical feedback process has changed - it has a different identity.

3. What could be the corresponding way to translate "Adaptive cycles (across scales)" to WASH systems?

The behavior of self-organizing systems changes over time due to internal processes. Systems undergo a period of rapid growth as they exploit new opportunities and resources. However, over time availability of resources is decreasing; connections are increasing. The system enters a phase of "conservation", which comes to an end in a collapse. Resources are lost, but it also opens the way for renewal and a new order rises up, and enters back in a phase of rapid growth.

\section{How do you translate "Scales are linked" to WASH systems?}

What happens at one scale can have a profound influence on what's happening at scales above it and on the embedded scales below.

5. Are there any "Tradeoffs between the two complementary aspects of resilience: specified resilience and general resilience?

Specified resilience is the resilience of a specified part of the system to a specific shock. General resilience is the capacity of a system that allows it to absorb disturbances of all kinds, including novel, unforeseen ones. Channeling all your efforts into one kind of resilience will reduce resilience in other ways.

\section{How do you see Transformation in WASH? How do you look at the Difference} between "adapting and transformation"?

Adaptability is the capacity of a social-ecological system to manage resilience-to avoid crossing thresholds, or to engineer a crossing to get back into a desired regime, 
or to move thresholds to create a larger safe operating space. Transformability is the capacity of a system to become a different system.

7. How do you see the "Tradeoffs between building resilience and not doing it?" Building resilience isn't free; it comes with both the direct costs of the actions you take and the indirect costs of opportunities lost. Enhancing the resilience of a system usually involves reducing efficiency, staying away from maximum yield states, maintaining reserves, and so forth. 